\title{
Kontribusi Teori Kognitif Robert M. Gagne dalam Pembelajaran Pendidikan Agama Islam
}

\author{
Rifqiyyatush Sholihah Al-Mahiroh \\ Universitas Islam Negeri Sunan Kalijaga Yogyakarta \\ rifqialmahiroh@gmail.com \\ Suyadi \\ Universitas Islam Negeri Sunan Kalijaga Yogyakarta \\ suyadi@uin-suka.ac.id
}

Naskah diterima: 16 April 2020 | Disetujui: 20 Juli 2020| Diterbitkan: 10 Agustus 2020

\begin{abstract}
This research is based on problems in the learning process of Islamic education (PAI) that is still focused on the side of educators. Hence it needs seriousness to create PAI learning that covers all aspects, including students, social and geographical environment. This study aims to determine the implementation of Robert M. Gagne's cognitive theory in PAI learning at the Al-Qur'an Science High School (SMA Sains Al-Qurán) in Yogyakarta. Conducted in qualitative research with a psychological approach and using the cognitive theory of Gagne's view, research data was collected through the observations to schools, interviews with PAI teachers, and relevant documentation. The results of this study note that the application of cognitive theory in the PAI learning successfully done through the nine instructional events of Robert M. Gagne (gaining attention, informing learners of the learning objectives, stimulating the recall of prior learning, presenting the stimulus of content, providing learning guidance, eliciting performance, providing feedback, assessing performance, and enhancing retention/transfer).
\end{abstract}

Keywords: cognitive theory, Islamic education learning, nine instructional events, Robert M. Gagne.

\begin{abstract}
Abstrak
Penelitian ini didasarkan pada permasalahan dalam proses pembelajaran Pendidikan Agama Islam (PAI) yang masih terfokus pada sisi pendidik. Oleh karena itu perlu keseriusan untuk menciptakan pembelajaran PAI yang mencakup semua aspek, termasuk siswa, lingkungan sosial dan geografis. Penelitian ini bertujuan untuk mengetahui implementasi teori kognitif Robert M. Gagne dalam pembelajaran PAI di SMA Sains Al-Qur'an Yogyakarta. Dilakukan dalam penelitian kualitatif dengan pendekatan psikologis dan menggunakan teori kognitif pandangan Gagne, data penelitian dikumpulkan melalui observasi ke sekolah, wawancara dengan guru PAI, dan dokumentasi yang relevan. Hasil penelitian ini mencatat bahwa penerapan teori kognitif dalam pembelajaran PAI berhasil dilakukan melalui sembilan langkah pembelajaran Robert M. Gagne (mendapatkan perhatian, menginformasikan peserta didik tentang tujuan pembelajaran, merangsang ingatan pembelajaran sebelumnya, menghadirkan rangsangan dari pembelajaran sebelumnya, memberikan bimbingan belajar, memantik kinerja, memberikan umpan balik, menilai kinerja, dan meningkatkan retensi dan transfer pengetahuan).
\end{abstract}

Kata Kunci: pembelajaran PAI, Robert M. Gagne, sembilan langkah pembelajaran, teori kognitif open access article under the CC BY-SA 4.0 license. doi: 10.37680/qalamuna.v12i2.353 


\section{Pendahuluan}

Belajar adalah sesuatu yang pasti terjadi dan dialami oleh manusia karena merupakan proses yang berlangsung selamanya dan dengan sadar dalam hidupnya. Proses belajar terjadi ketika seseorang berinteraksi dengan lingkungannya kapan saja dan di mana saja. Seseorang yang telah belajar akan mengalami perubahan tingkah laku pada dirinya, baik dalam bentuk pengetahuan dan keterampilan baru maupun dalam bentuk sikap dan nilai yang positif (Basleman \& Mappa, 2011). Belajar merupakan aktifitas yang dilakukan sehari-hari, yang membuat manusia berbeda dari makhluk Allah yang lain karena telah diberi kesempurnaan akal untuk dapat berfikir sehingga memiliki kesempatan yang luas dan tak terbatas untuk dapat meningkatkan kapasitas diri dengan mendapat pengetahuan yang baru.

Banyak teori yang menjelaskan secara detail proses belajar berlangsung, dan setiap teori memiliki prinsip serta konsep yang berbeda. Menurut Kosmiyah (2012), beberapa teori belajar yang relevan dan dapat diterapkan dalam kegiatan pembelajaran, antara lain: 1) teori belajar humanisme, yaitu proses belajar yang dilakukan untuk memanusiakan manusia dengan tercapainya aktualisasi diri pada siswa secara optimal; 2) teori belajar konstruktivisme, yaitu menyusun pengetahuan dari pengalaman konkret, aktivasi kolaborasi, refleksi serta interpretasi; 3) teori belajar sibernetik, yaitu proses belajar dengan mengolah informasi (pesan pembelajaran) yang ditentukan oleh sistem informasi kemudian; dan 4) teori belajar kognitif, yakni pengorganisasian aspek kognitif dan persepsi untuk memperoleh suatu pemahaman.

Pembelajaran merupakan serangkaian kegiatan belajar yang diselenggarakan oleh guru sebagai upaya memberikan pembelajaran kepada siswa mengenai cara mendapat dan memproses pengetahuan, keterampilan, dan sikap (Dimyati \& Mudjiono, 2002). Pembelajaran sebagai upaya mengembangkan potensi siswa menjadi kompetensi, sedangkan para perancang pembelajaran atau guru, serta para pengembang program yang profesional perlu memilih dan mampu mengaplikasikan teori belajar yang tepat untuk diterapkan dalam pembelajaran. Kegiatan pembelajaran harus dilakukan secara profesional, serta sesuai dengan teori dan prinsip belajar tertentu. Melalui teori belajar, diharapkan dapat mengarahkan dalam merancang dan melaksanakan kegiatan pembelajaran, sehingga para pengembang program pembelajaran dapat memilih teori belajar yang tepat untuk digunakan dalam mendesain pembelajaran yang akan dilakukan. Contohnya, dengan mengaplikasikan teori belajar kognitif, diharapkan mampu memberikan arahan, membimbing seseorang dalam merancang dan melaksanakan kegiatan pembelajaran yang akan dilaksanakan (Kosmiyah, 2012).

Tidak semua teori belajar relevan dan dapat diimplementasikan dalam pembelajaran, namun dapat memberi arahan dan hal yang menjadi prioritas dalam pelaksanaan pembelajaran, sehingga kegiatan pembelajaran tidak dapat dilakukan sembarangan tanpa didasari teori dan prinsip belajar yang tepat digunakan (Dimyati dan Mudjiono, 2002). Salah satu teori belajar kognitif adalah teori yang dikemukakan oleh Robert M. Gagne yang disebut dengan teori pembelajaran Gagne. Teori ini sebagai bentuk rangkaian langkah belajar yang mengategorikan situasi belajar berdasarkan peristiwa belajar, kemampuan belajar, dan pembagian tipe hasil belajar.

Teori belajar Robert M. Gagne merupakan perpaduan yang seimbang antara behaviorisme dan kognitisme yang berpangkal pada teori pemrosesan informasi (Ratumanan, 2004). Pada teori pemrosesan informasi, timbul adanya interaksi antara kondisi internal dan eksternal individu. Kondisi internal sebagai keadaan diri individu yang dibutuhkan untuk mencapai hasil belajar dan 
proses kognitif yang terjadi dalam diri individu sedangkan kondisi eksternal sebagai rangsangan dari lingkungan yang dapat mempengaruhi individu dalam pembelajaran. Kondisi eksternal ini disebut sembilan langkah pembelajaran yang sesuai dengan teori Gagne (Suyono \& Hariyanto, 2011).

Berdasarkan model belajar pemrosesan informasi, Gagne menjelaskan delapan fase dalam satu tindakan belajar (learning act). Fase tersebut adalah kejadian eksternal yang dapat distrukturkan oleh subjek pembelajar. Setiap fase dipasangkan dengan suatu proses yang terjadi dalam pikiran siswa, fase-fase tersebut adalah: (Dahar, 2011)

1. Fase Motivasi, merupakan fase pemberian harapan kepada siswa, bahwasanya siswa akan mampu memenuhi keingintahuan terhadap suatu pembahasan.

2. Fase Pengenalan, yaitu fase yang di mana siswa harus memberikan perhatian pada bagian esensial suatu kejadian instruksional ketika proses belajar berlangsung.

3. Fase Perolehan, yaitu fase siswa memperhatikan informasi yang relevan sebagai wujud siswa telah siap menerima pelajaran.

4. Fase Retensi, yaitu fase di mana informasi baru dipindahkan dari memori jangka pendek (short term memory) ke memori jangka panjang (long term memory). Hal ini bisa terjadi melalui pengulangan kembali, praktik, elaborasi atau lainnya.

5. Fase Pemanggilan, adalah fase kemampuan mengungkap keluar informasi yang telah dimiliki dan disimpan dalam ingatan.

6. Fase Generalisasi, fase di mana siswa belajar memanfaatkan informasi yang didapat ke dalam permasalahan yang relevan dalam kehidupan sehari-hari

7. Fase Penampilan, yaitu fase siswa mampu menampilkan atau memperlihatkan keterampilan sebagai hasil belajar.

8. Fase Umpan Balik, siswa memperoleh umpan balik mengenai penampilan mereka sebagai bentuk evaluasi terhadap kemampuan yang dimiliki siswa.

Menurut Gagne, pengajaran itu sebagai upaya pendidik dalam meyakinkan kepada siswa akan kemampuan yang dimiliki sebagai syarat dalam menyelesaikan tugas serta memberikan stimulus sehingga siswa mampu mengatur dan menyelesaikan pembelajarannya dengan baik. Pembelajaran itu sendiri hendaknya mampu memunculkan peristiwa belajar dan proses kognitif sehingga pembelajaran dapat berlangsung dengan baik. Salah satu teori pembelajaran yang dapat diterapkan adalah teori Robert M. Gagne yang dikenal dengan model nine instructional events atau sembilan langkah pembelajaran. Pada praktiknya, teori ini memudahkan dalam penyusunan rancangan kegiatan belajar mengajar yang akan dilakukan (Warsita, 2018).

Salah satu sekolah yang sudah menerapkan teori Robert M. Gagne dalam proses pembelajarannya adalah SMA Sains Al-Qur'an, salah satu lembaga pendidikan menengah formal yang berada di bawah naungan Yayasan Pondok Pesantren Wahid Hasyim Yogyakarta. Sekolah yang mengintegrasikan kurikulum nasional dengan kurikulum unggulan pesantren tersebut baru berdiri pada tahun 2014, namun sudah banyak menorehkan prestasi tingkat nasioanal maupun internasional dalam bidang akademik maupun non-akademik. Tentunya sistem pembelajaran juga didesain dengan kreatif dan inovatif dalam memenuhi tuntutan zaman. Salah satu mata pelajaran pokok yang menjadi pelajaran khas pesantren dengan ditambahkannya program pesantren di dalamnya adalah PAI. Karakteristik siswa yang kritis dalam pembelajaran PAI, apalagi dengan mengingat urgensi pemahaman PAI dengan baik agar dapat menyiapkan peserta didik untuk 
menyongsong tantangan masa depan (Salamah, 2020; Achadah, 2020), tentunya perlu diimbangi dengan pemilihan model pembelajaran yang tepat. Berdasarkan hasil wawancara dengan salah satu guru PAI di sekolah tersebut, yaitu Ibu Nur Kholifatun Nazilah, M.Pd., beliau mengatakan bahwa salah satu model pembelajaran yang digunakan adalah model pembelajaran Robert M. Gagne, karena model pembelajarannya sesuai tahapan pembelajaran yang diterapkan di SMA Sains AlQur'an. Oleh karena itu, peneliti melakukan penelitian di lembaga ini dengan tujuan untuk mengetahui penerapan atau implementasi dari teori kognitif Robert M. Gagne dalam pembelajaran PAI di SMA Sains Al-Qur'an Yogyakarta.

\section{Metode}

Penelitian ini merupakan penelitian kualitatif dengan pendekatan psikologi dan memakai teori kognitif pandangan Robert M. Gagne. Teknik pengumpulan data yang peneliti gunakan adalah observasi ke sekolah, wawancara dengan guru PAI, dan studi dokumentasi terkait dengan penelitian. Subjek penelitian yang digunakan adalah siswa kelas XI dan satu guru PAI yang mengajar pada kelas tersebut. Analisis data dilaksanakan dalam tiga tahapan dan melalui tiga jalur analisis data kualitatif, yaitu reduksi data, penyajian data, dan penarikan kesimpulan (Miles \& Huberman, 1992). Reduksi data adalah proses pemilihan, pemusatan perhatian pada penyederhanaan, pengabstrakan dan transformasi data kasar yang muncul dari catatan-catatan tertulis di lapangan, sedangkan penyajian data adalah kegiatan ketika sekumpulan informasi disusun sehingga memberi kemungkinan akan adanya penarikan kesimpulan serta pengambilan tindakan.

\section{Sembilan Langkah Pembelajaran Robert M. Gagne}

Belajar memberikan sumbangsih terhadap apa yang dikembangkan sebagai suatu proses yang logis lalu perkembangan tingkah laku atau behavior adalah hasil proses belajar secara keseluruhan. Prinsip-prinsip pembelajaran dari Robert M. Gagne adalah: a) Perhatian minat motivasi belajar siswa, b) Keterlibatan dan keaktifan langsung siswa dalam pembelajaran, c) mengulang atau mempelajari pelajaran yang lalu, d) menghadapi tantangan dan semangat dalam belajar, e) memberikan timbal balik dan melakukan penguatan belajar, dan f) adanya perbedaan dalam perilaku belajar siswa. Lebih dari itu, hal yang harus diperhatikan adalah tentang terciptanya kondisi belajar yang kondusif, pada lingkungan belajar, pada kondisi berbasis media, meliputi jenis penyajian yang disampaikan kepada siswa dengan adanya jadwal, pengurutan, dan pengorganisasian (Gagne, 1990).

Pembelajaran adalah hal yang krusial dari proses pendidikan di sekolah, maka diperlukan pengelolaan yang baik dalam kegiatan pembelajaran agar tujuan pendidikan dapat tercapai. Banyak hal yang dapat mempengaruhi proses pembelajaran, di antaranya: siswa, metode, tenaga pendidik atau guru, sarana prasarana, serta evaluasi (penilaian hasil belajar). Guru menjadi bagian yang paling bertanggung jawab dalam kegiatan pembelajaran, karena bilamana pengelolaan pembelajaran oleh guru baik maka tujuan pembelajaran dapat tercapai dengan mudah.

Proses kegiatan belajar mengajar yang baik yaitu dititikberatkan pada keaktifan peserta didik (Effendi, 2016). Hal ini mengharuskan guru/pendidik untuk aktif dan kreatif dalam membuat lingkungan belajar kondusif serta menantang. Tujuan pembelajaran akan tercapai dengan baik bilamana cara belajar siswa dapat aktif berlangsung secara efektif tentunya atas peran pendidik 
dalam melaksanakan peran serta fungsinya secara aktif dan kreatif. Kemampuan guru/pendidik dalam memilih metode dan pendekatan yang tepat menjadi dasar berhasilnya penyampaian materi kepada siswa supaya timbul aktivitas, minat, dan kualitas proses belajar yang meningkat. Oleh karena itu, guru/pendidik harus memperhatikan beberapa tahapan pembelajaran, dari kegiatan perencanaan, pelaksanaan pembelajaran, penilaian dan tindak lanjut pembelajaran.

Proses berubahnya tingkah laku setiap individu yang berasal dari interaksi individu tersebut dengan sumber belajar yang ada di lingkungannya merupakan sebuah konsep belajar. Perubahan tingkah laku tersebutlah yang dinamakan dengan tanda orang tersebut telah belajar. Perubahan tingkah laku tersebut mencakup sikap (afektif). pengetahuan (kognitif), dan keterampilan (psikomotor), sehingga dapat disimpulkan bahwa belajar adalah serangkaian proses seseorang untuk mencapai kecakapan, ketrampilan, dan juga sikap (Gredler, 1994).

Proses belajar sesungguhnya tergantung individu masing-masing meskipun kegiatannya dilakukan secara bersama atau berkelompok. Konsep belajar yang harus dimiliki adalah upaya untuk mengingat dan upaya untuk memahami, serta untuk menerapkan (melakukan, keterampilan, praktik). Belajar merupakan pengembangan diri yang dimiliki manusia, sehingga proses pembelajaran ini akan bermakna di mana guru memfasilitasi siswa dalam hal proses mental melalui tindakan yang nyata.

Gagne mengembangkan pemrosesan informasi dalam pembelajaran dengan mengenai model proses belajar yang meliputi: 1) informasi yang berasal dari stimulus yang diterima oleh panca indra kemudian disalurkan ke pusat syaraf, 2) pemilihan informasi dilakukan secara selektif, dalam arti ada yang tersimpan dalam memori jangka pendek atau jangka panjang, bahkan ada yang terbuang atau terlupakan, 3) memori yang ada tercampur dengan memori baru, dan setelah diolah sehingga dapat diungkapkan kembali (1990).

Menurut Gagne (1990), sebaiknya pembelajaran itu mampu menumbuhkan kegiatan belajar mengajar dan proses kognitif yang baik. Proses pembelajaran (instructional events) adalah sebagai berikut: 1) menumbuhkan minat dan memfokuskan perhatian siswa; 2) menyampaikan tujuan dari kegiatan belajar; 3) mereview pelajaran sebelumnya; 4) menyampaikan materi-materi pada proses pembelajaran; 5) memberikan arahan kepada siswa tentang petunjuk belajar; 6) memberikan stimulus agar siswa tergugah untuk memberikan respon; 7) memberikan penguatan atau umpan balik atas pekerjaan yang diberikan kepada siswa; 8) melakukan evaluasi pembelajaran; dan 9) memperkuat retensi proses belajar siswa (Suyono \& Hariyanto, 2011).

Sembilan langkah pembelajaran tersebut merupakan sebuah kegiatan yang disusun oleh pendidik untuk membantu proses belajar siswa. Meski demikian, tidak semua langkah yang ada dapat atau harus ditetapkan pada seluruh mata pelajaran yang ada. Bentuk pengembangannya diserahkan kepada pendidik sesuai dengan kompetensi dasar yang ada demi berjalannya proses belajar siswa sebagaimana dapat disimak secara detail dalam Tabel 1. 
Tabel 1. Instructional Events and Cognitive Process (diadaptasi dari Zhu \& St. Amant, 2010)

\begin{tabular}{|c|c|c|}
\hline No. & Peristiwa & Penjelasan \\
\hline 1 & $\begin{array}{l}\text { Gaining attention } \\
\text { (memberikan perhatian) }\end{array}$ & $\begin{array}{l}\text { Pada proses awal pembelajaran menarik perhatian } \\
\text { siswa, sehingga siswa diharapkan siap dan fokus } \\
\text { dalam mengikuti pembelajaran. Perhatian siswa } \\
\text { dapat ditingkatkan dengan memberikan rangsangan } \\
\text { sesuai dengan kognisi yang ada. }\end{array}$ \\
\hline 2 & $\begin{array}{l}\text { Informing learners of the } \\
\text { objectives of the overall } \\
\text { Training (memberitahu } \\
\text { siswa tentang tujuan } \\
\text { belajar) }\end{array}$ & $\begin{array}{l}\text { Dilakukan agar siswa mengerti dan mempunyai } \\
\text { tujuan dan harapan belajar, agar siswa mampu } \\
\text { menemukan sendiri esensi dari belajar tersebut, } \\
\text { kemudian sampaikan manfaat apa yang akan } \\
\text { didapatkan dari pembelajaran tersebut serta } \\
\text { pemberian tugas kepada siswa. }\end{array}$ \\
\hline 3 & $\begin{array}{l}\text { Stimulating the recall of } \\
\text { prior } \quad \text { learning } \\
\text { (Membangun } \quad \text { kembali } \\
\text { pengetahuan yang lalu) }\end{array}$ & $\begin{array}{l}\text { Siswa perlu mengingat kembali materi yang telah } \\
\text { dipelajari sebelumnya kemudian mengintegrasikan } \\
\text { dengan materi-materi yang akan dipelajari. }\end{array}$ \\
\hline 4 & $\begin{array}{l}\text { Presenting the stimulus/ } \\
\text { content (information) } \\
\text { (menyajikan pembelajaran } \\
\text { sebagai rangsangan }\end{array}$ & $\begin{array}{l}\text { Ketika menjelaskan materi pembelajaran, guru } \\
\text { menggunakan contoh, serta disampaikan dan } \\
\text { dikemas secara menarik. }\end{array}$ \\
\hline 5 & $\begin{array}{l}\text { Providing learning } \\
\text { Guidance (Memberi } \\
\text { panduan belajar) }\end{array}$ & $\begin{array}{l}\text { Diberikannya arahan serta bimbingan dan pedoman } \\
\text { dalam rangka memudahkan siswa mencapai tujuan } \\
\text { selama proses pembelajaran dengan cara } \\
\text { memberikan beberapa pertanyaan pada siswa. }\end{array}$ \\
\hline 6 & $\begin{array}{l}\text { Eliciting performance } \\
\text { (menampilkan kinerja) }\end{array}$ & $\begin{array}{l}\text { Siswa diminta untuk menjelaskan kepada guru } \\
\text { terkait dengan materi telah dipelajari, untuk } \\
\text { meyakinkan guru ataupun dirinya sendiri dalam } \\
\text { bentuk tindakan untuk menampilkan } \\
\text { kemampuannya. }\end{array}$ \\
\hline 7 & $\begin{array}{l}\text { Providing feedback } \\
\text { (memberikan umpan } \\
\text { balik) }\end{array}$ & $\begin{array}{l}\text { Guru memberikan umpan balik untuk membantu } \\
\text { siswa mengetahui tentang pemahamannya serta } \\
\text { bagaimana hasil unjuk kerja yang dihasilkannya. }\end{array}$ \\
\hline 8 & $\begin{array}{l}\text { Assessing performance } \\
\text { (menilai kinerja) }\end{array}$ & $\begin{array}{l}\text { Bagian dari peristiwa pembelajaran yang berfungsi } \\
\text { menilai kemampuan siswa, sehingga perlu dibuat alat } \\
\text { penilaian yang konsisten agar dapat mengukur } \\
\text { tingkat pencapaian belajar siswa. }\end{array}$ \\
\hline 9 & $\begin{array}{l}\text { Enhancing retention and } \\
\text { Transfer (meningkatkan } \\
\text { retensi/ingatan dan } \\
\text { transfer pengetahuan) }\end{array}$ & $\begin{array}{l}\text { Guru memberikan latihan kepada siswa untuk } \\
\text { memberdayakan pengetahuan yang ia dapat } \\
\text { kapanpun waktunya. }\end{array}$ \\
\hline
\end{tabular}


Berkaitan dengan langkah-langkah tersebut, dalam proses pembelajaran yang terjadi di SMA Sains Al-Qur'an dari obeservasi dan wawancara peneliti, peneliti menemukan beberapa temuan yang terkait dengan implementasi Teori Belajar Robert M. Gagne dalam pembelajaran PAI.

\section{Sembilan Langkah Belajar Gagne dalam Pembelajaran PAI di SMA Sains Al-Qur'an}

Langkah pertama dalam pembelajaran, yaitu gaining attention (memberikan perhatian) di mana siswa dipersiapkan dengan baik secara fisik dan psikis dalam memulai pembelajaran PAI. Di SMA Sains Al-Qur'an, siswa diajak untuk mengawali dengan membaca asmaul husna (99 nama Allah), kemudian dilanjut membaca kaidah talfiful akwan, lalu mengawali pembelajaran dengan permainan yang menyenangkan agar dapat menimbulkan minat dan perhatian siswa seperti Tes Konsentrasi. Tahapan ini sangat penting, karena apabila siswa tertarik dengan pembelajaran di awal, maka siswa akan mengikuti dengan baik pembelajaran hingga akhir. Secara teknis, penempatan posisi duduk siswa juga dapat diatur sedemikian rupa agar dapat meningkatkan atensi, sebagaimana tampak dalam Gambar 1.

Langkah kedua yaitu informing learners of the objectives of the overall training (memberitahu siswa tentang tujuan belajar). Guru menyampaikan tujuan pembelajaran, kemudian siswa diberi penjelasan mengenai bagaimana pengaruh atau manfaat belajar PAI dalam kehidupan sehari-hari.

Langkah ketiga yaitu stimulating the recall of prior learning (membangun kembali pengetahuan yang lalu). Guru mengaitkan atau membahas kembali materi yang telah disampaikan pada pertemuan sebelumnya, salah satunya dengan cara menanyakan hal yang terdapat kaitan dengan materi yang akan dipelajari. Langkah keempat yaitu presenting the stimulus/content (information) (menyajikan pembelajaran sebagai rangsangan). Dalam tahapan ini, metode yang digunakan guru tidak hanya ceramah, melainkan juga metode lain yang menyenangkan seperti metode diskusi dan/atau presentasi.

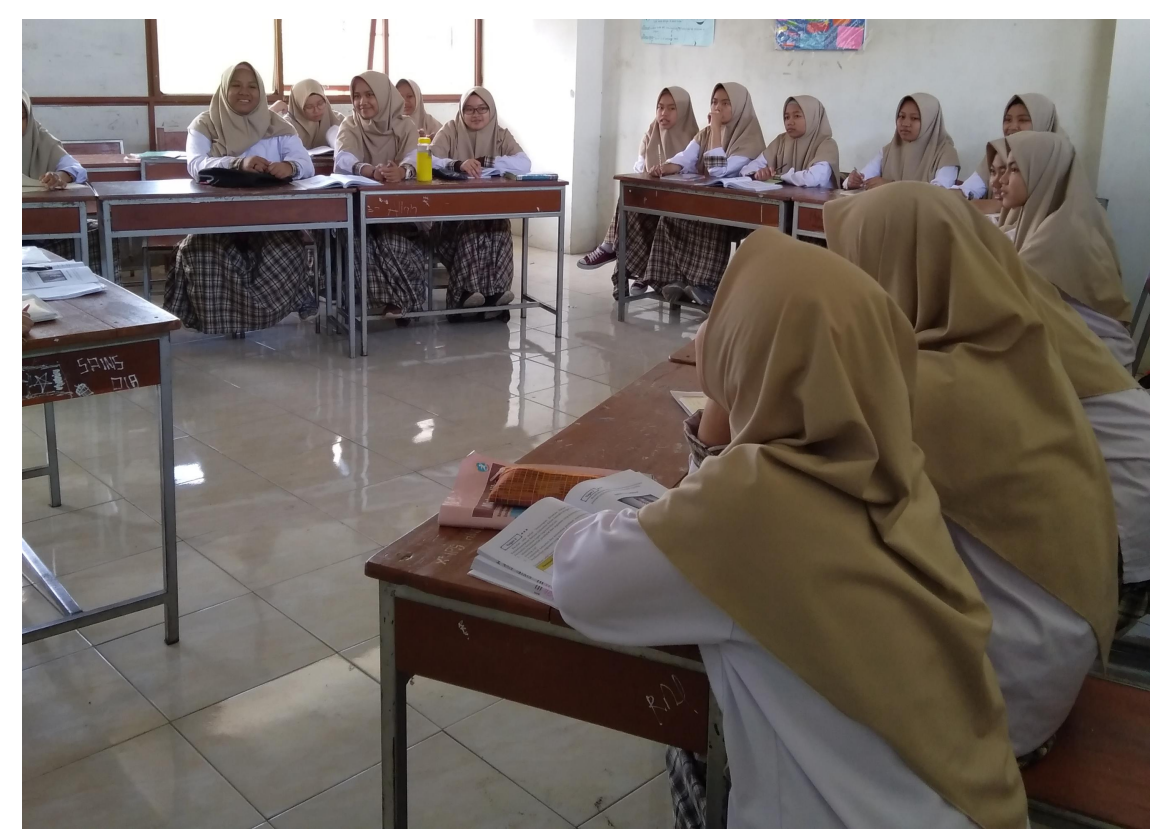

Gambar 1. Guru melakukan opening dan mengondisikan siswa untuk siap belajar. 
Langkah kelima yaitu providing learning guidance (memberi panduan belajar). Siswa diberi pertanyaan seputar materi dan juga diminta memberi pertanyaan lagi yang ditujukan kepada temannya. Langkah keenam adalah eliciting performance (menampilkan kinerja) di mana siswa diberikan permasalahan yang terkait dengan materi dan berdiskusi dengan temannya. Kemudian, salah satu siswa diarahkan untuk berdiri di depan kelas dan menyampaikan hasil diskusinya (Gambar 2).

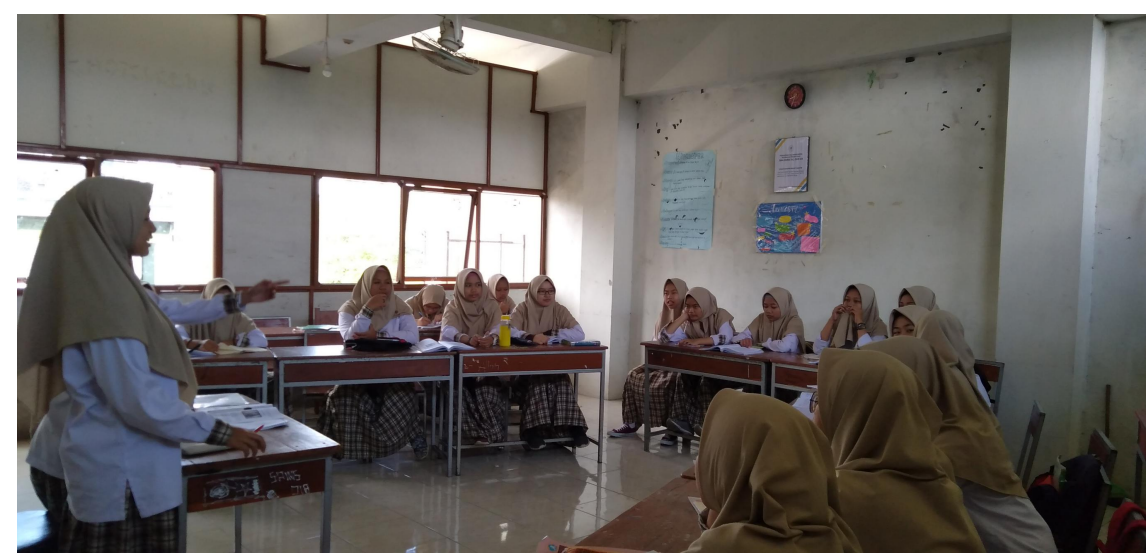

Gambar 2. Siswa melaksanakan langkah eliciting performance (menampilkan kinerja).

Langkah ketujuh yaitu providing feedback (memberikan umpan balik). Guru memberikan timbal balik ke siswa dan penguatan materi dari unjuk kerja siswa yang dihasilkan. Kemudian langkah kedelapan, assessing performance (menilai kinerja), di mana siswa diberikan soal atau pekerjaan individu untuk mengukur ketercapaian tujuan pembelajaran (Gambar 3). Guru membuat alat ukur yang akurat dan konsisten. Dan yang terakhir adalah langkah kesembilan, yakni enhancing retention and transfer (meningkatkan retensi/ingatan dan transfer pengetahuan). Dalam tahapan ini, siswa diberikan tugas agar siswa dapat mengulangi dan menggunakan pengetahuan barunya tersebut di waktu yang lain.

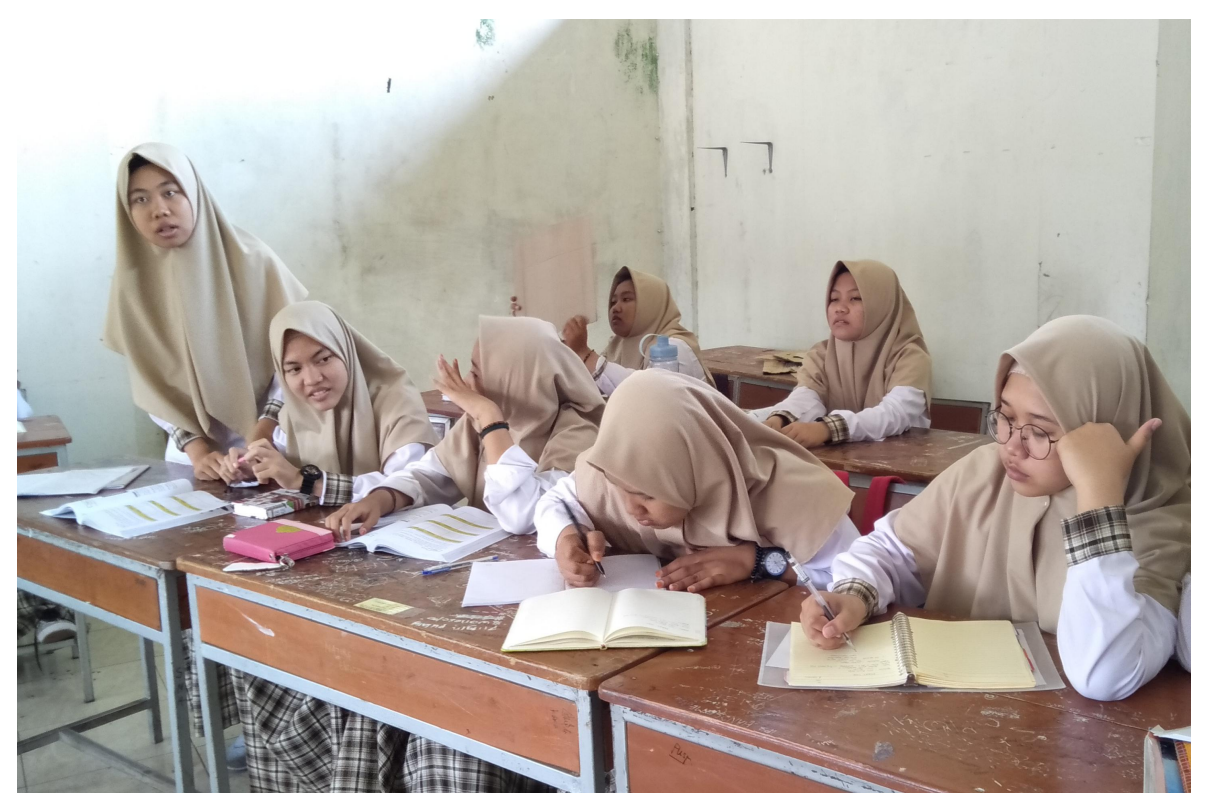

Gambar 3. Guru memberikan feedback lalu siswa diberikan soal atau project untuk mengukur ketercapaian tujuan pembelajaran (assessing performance) 


\section{Kesimpulan}

Berkaitan dengan hasil penelitian di atas, pembelajaran yang terjadi di SMA Sains Al-Qur'an sudah mengimplementasikan Teori Robert M. Gagne yang dikenal dengan teori nine instructional events atau sembilan langkah pembelajaran. Tahapan pertama adalah mengarahkan perhatian siswa, karena bentuk respons siswa di awal akan menentukan pembelajaran hingga akhir, kemudian menyampaikan tujuan pembelajaran sebagai upaya agar siswa memahami tujuan pembelajaran yang akan dicapai serta mengetahui kompetensi yang harus dikuasai selama pembelajaran.langkah berikutnya adalah memberikan stimulus yang membuat siswa bisa terlibat langsung. Kemudian siswa diberi bimbingan belajar dengan menggunakan metode yang menarik. Setelah dilakukan proses pembelajaran siswa diminta untuk menunjukan hasil dari unjuk kerja berdasar tugas yang diberikan guru di depan umum dengan melalui presentasi lalu memberikan penilaian. Di akhir pembelajaran, guru memberikan retensi atau materi yang telah diajarkan. Tahap-tahap belajar Robert M. Gagne memiliki kontribusi terhadap sistem pengajaran, khususnya dalam pembelajaran PAI di SMA Sains Al-Qur'an yang terbantu dalam menentukan pola dan langkah-langkah pembelajarannya.

\section{Bibliografi}

Achadah, A. (2020). MODEL INOVASI PENGEMBANGAN KURIKULUM PAI UNTUK MENGHADAPI REVOLUSI INDUSTRI 4.0. SCAFFOLDING: Jurnal Pendidikan Islam dan Multikulturalisme 2 (1), 1-10 https://doi.org/10.37680/scaffolding.v2i1.260

Adawiyah, R. \& Widiana, H. (2009). Motivasi Belajar dalam Mempelajari Agama Islam Ditinjau dari Metode Pembelajaran. Jurnal Psikologi, 2(2), 151-165.

Basleman, A. \& Mappa, S. (2011). Teori Belajar Orang Dewasa. Bandung: Remaja Rosdakarya.

Dahar, R. (2011). Teori-Teori Belajar \& Pembelajaran. Jakarta: Erlangga

Dimyati \& Mudjiono. (2002). Belajar dan Pembelajaran. Jakarta: PT. Rineka Cipta

Effendi, M. (2016). Integrasi Pembelajaran Active Learning dan Internet-Based Learning dalam Meningkatkan Keaktifan dan Kreativitas Belajar. Nadwa, 7(2), 283-309. doi:http://dx.doi.org/10.21580/nw.2013.7.2.563

Gagne, R. (1990). The Condition of Learning. (Third ed). New York: Holt, Rinehart and Winstone. Gredler, M. (1994). Belajar dan Pembelajaran. Jakarta: Penerbit PT. Raja Grafindo Persada.

Kosmiyah, I. (2012). Belajar dan Pembelajaran. Yogyakarta: Teras

Miles, B. \& Huberman, M. (1992). Analisis Data Kualitatif Buku Sumber Tentang Metode-metode Baru. Jakarta: UIP.

Moleong, L. (2004). Metode Penelitian Kualitatif. Bandung; Remaja Rosdakarya.

Ratumanan, T. (2004). Belajar dan Pembelajaran. Surabaya: Unesa University Press.

Salamah, S. (2020). PERAN GURU PAI DALAM PEMBENTUKAN KARAKTER SISWA DI ERA REVOLUSI INDUSTRI 4.0. SCAFFOLDING: Jurnal Pendidikan Islam dan Multikulturalisme 2 (1), 12-21 https://doi.org/10.37680/scaffolding.v2i1.281

Suyono \& Hariyanto. (2011). Belajar dan Pembelajaran. Bandung: Remaja Rosdakarya.

Warsita, B. (2018). TEORI BELAJAR ROBERT M. GAGNE DAN IMPLIKASINYA PADA PENTINGNYA PUSAT SUMBER BELAJAR. Jurnal Teknodik, 12(1), 064. https://doi.org/10.32550/teknodik.v12i1.421 
Kontribusi Teori Kognitif Robert M. Gagne dalam Pembelajaran Pendidikan Agama Islam

- Rifqiyyatush Sholihah Al-Mahiroh \& Suyadi

Zhu, P., \& St. Amant, K. (2010). An Application of Robert Gagné's Nine Events of Instruction to the Teaching of Website Localization. Journal of Technical Writing and Communication, 40(3), 337-362. https://doi.org/10.2190/TW.40.3.f 